Journal of Patient-Centered

\title{
8-15-2016
}

\section{Sharing Experiences and Expertise: The Health Care Systems Research Network Workshop on Patient Engagement in Research}

\author{
Sarah Madrid \\ Leah Tuzzio \\ Cheryl D. Stults \\ Leslie A. Wright \\ Gina Napolitano \\ Ellis Dillon \\ Heather Tabano \\ Sarah M. Greene
}

Follow this and additional works at: https://aah.org/jpcrr

Part of the Health Services Research Commons, Medical Humanities Commons, and the Translational Medical Research Commons

\section{Recommended Citation}

Madrid S, Tuzzio L, Stults CD, Wright LA, Napolitano G, Dillon E, Tabano H, Greene SM. Sharing experiences and expertise: the Health Care Systems Research Network workshop on patient engagement in research. J Patient Cent Res Rev. 2016;3:159-66. doi: 10.17294/2330-0698.1272

Published quarterly by Midwest-based health system Advocate Aurora Health and indexed in PubMed Central, the Journal of Patient-Centered Research and Reviews (JPCRR) is an open access, peer-reviewed medical journal focused on disseminating scholarly works devoted to improving patient-centered care practices, health outcomes, and the patient experience. 


\title{
Sharing Experiences and Expertise: The Health Care Systems Research Network Workshop on Patient Engagement in Research
}

\author{
Sarah Madrid, MA, ${ }^{1}$ Leah Tuzzio, MPH,${ }^{2}$ Cheryl D. Stults, PhD, ${ }^{3}$ Leslie A. Wright, MPH,${ }^{1}$ Gina \\ Napolitano, MSW, LCSW, ${ }^{4}$ Ellis Dillon, PhD, ${ }^{3}$ Heather Tabano, MHA, ${ }^{1}$ Sarah M. Greene, $\mathrm{MPH}^{5}$ \\ ${ }^{1}$ Institute for Health Research, Kaiser Permanente Colorado, Denver, CO \\ ${ }^{2}$ Group Health Research Institute, Seattle, WA \\ ${ }^{3}$ Palo Alto Medical Foundation Research Institute, Palo Alto, CA \\ ${ }^{4}$ Patient author, no health care affiliation \\ ${ }^{5}$ Health Care Systems Research Network, Seattle, WA
}

\begin{abstract}
The Health Care Systems Research Network's (HCSRN) Patient Engagement in Research Scientific Interest Group (PER SIG) held a half-day workshop for researchers attending HCSRN's 22nd annual conference, April 16, 2016, in Atlanta, Georgia. The workshop blended didactic and interactive content to facilitate co-learning. Both researchers and patient partners developed the content, including three broad topics: engagement of patient partners in developing research studies, nurturing partnerships, and assessing the impact of patient engagement in research. Each module presented approaches relevant to the specific topic, including lessons from the literature and in-the-field experience. Patient partners reflected on their experience related to each module, and the interactive portion included small group exercises and in-depth discussion. Workshop attendees $(n=32)$ collectively contributed to suggestions for future work in the area of patient-engaged research. Conclusions reached by workshop planners and attendees included the recognition that engaging patient partners in research requires a set of skills not normally used or even valued in scientific research methods and requires longer timelines than those generally accepted by research funding organizations. Effective engagement requires a paradigm shift from researchers as all-knowing to scientific team members who acknowledge the importance of patient partners as co-equal. When engaging patients in research, every aspect of engagement should be conducted with an emphasis on equality among partners and the stated agreement that patient partners bring valid expertise — their experiences as patients — to the research process. (J Patient Cent Res Rev. 2016;3:159-166.)
\end{abstract}

Keywords patient engagement; research; methods

The Health Care Systems Research Network (HCSRN) is a collaboration of more than 1,900 researchers from health care systems across the United States dedicated to improving individual and population health through research. The HCSRN's Patient Engagement in Research Scientific Interest Group (PER SIG) was formed in 2014 and is comprised of scientists, research staff and patient research partners. It works to identify and disseminate

Correspondence: Sarah Madrid, MA, Institute for Health

Research, 10065 E. Harvard Avenue, Suite 300, Denver, CO, 80231, T: 303-614-1358, F: 303-614-1395,

Email: Sarah.Madrid@kp.org best practices in engagement methodologies and to develop generalizable engagement tools and resources through monthly conference calls as well as concurrent sessions and poster sessions at annual conferences.

The PER SIG offers engagement consulting services for research teams and developed the "Patient Engagement in Research Workbook" to provide guidance on basic methods of engaging patients in research. ${ }^{1}$ Given the recent focus on engaging patients in research through funding organizations like the Patient-Centered Outcomes Research Institute (PCORI), the 2016 HCSRN conference invited patient partners to serve as discussants in a plenary luncheon and included a half- 
day workshop (hosted by the PER SIG) to enhance researchers' engagement skills.

The workshop planning committee and faculty, which included five researchers and two patient partners, designed and conducted the workshop modules to ensure that patient perspectives were discussed for each topic. The workshop focused on identifying and disseminating best practices in patient engagement and creating a community of committed and knowledgeable researchers.

A total of 32 individuals attended the workshop, which aimed to foster discussion and the sharing of expertise as well as identify areas for continued empirical work chiefly focused on assessing impacts of patientengaged research. Participants ranged from novices to those with substantial experience working with patient partners.

Herein we describe the three workshop modules - 1) preaward and early engagement of patient partners; 2) caring for and maintaining established relationships; and 3) exploring frameworks and measures to assess the impacts of patient engagement - and report the main takeaways from the workshop.

\section{Module I: Preaward and Early Engagement}

During this module, facilitators shared experiences and best practices for identifying and working with patient partners during the proposal writing and preaward phase. Participants agreed that engaging patients early in the conception of a project is important for ensuring relevance of the research question and usability of the results. The facilitators reviewed essential first steps in preparing for patient partnerships in the research study context (Box 1).

\section{Box 1: Initial Needs Assessment* and Preparations}

1. Is the team open to patient perspectives?

2. Is the study timeline sufficient to meaningfully engage patient partners?

3 . Is the budget sufficient to compensate patient partners and provide needed resources (e.g. staff time to coordinate trainings, communication, meals, etc.)?

4. What contractual, human resource or institutional review board requirements are involved?

*The assessment should result in clear rationale for patient engagement, and commitment from the project team on whether to move forward.
Planning the patient partner role: Patient partner roles can vary depending on the needs of the study, funder requirements or an organization's research portfolio. The spectrum of engagement ranges from task- or phase-specific input, to providing guidance at periodic meetings, to the additional responsibilities and time commitment of a co-investigator. Patient partners often serve on research advisory panels, providing insight and advice on several research projects within a given portfolio. Workshop participants agreed that roles should be defined in the context of the specific study aims and timeline, and refined in collaboration with the patient partner(s). It was noted that role decisions have direct budget implications for compensation (hours plus reimbursement for child care or transportation). Patient partner compensation should reflect the level of expertise, responsibility and time commitment. If a partner's role includes dissemination activities, the budget could include potential expenses associated with conference travel.

"Involving me early in the planning stages allowed me to take ownership of the information and goals of the project. The work becomes 'ours' versus 'theirs.' My early involvement also allowed for a more cohesive research team to form, a team with shared expectations and goals."

- Gina Napolitano, patient partner

Recruiting patient partners: Identifying and recruiting patient partners is often challenging. Methods discussed included outreach through support groups, providers, social media, clinic flyers and word of mouth. Two novel approaches in development at the Institute for Health Research (Kaiser Permanente Colorado, Denver, CO) would generate a network of patients who have indicated interest in joining research teams by: 1) including an addendum to the informed consent template inviting research participants to provide their name and email address if they are interested in becoming engaged in research; or 2) emailing an invitation to a random sample of patients that provides a link to a website ${ }^{2}$ at which the potential patient partner can join a network and provide personal information to facilitate matching with a research team.

Vetting patient partners during an in-person meeting is an important step that benefits both parties. It allows 
mutual assessment of the potential fit with the team and the study, and also may alert the team to potential biases the patient may hold that could impact group dynamics. All conversations should communicate to the potential partner that their concerns, questions, ideas and contributions are heard and valued, and provide a model for subsequent interactions. Clarifying that participation is contingent on funding is critical for managing expectations, as is a communication plan in the interim until receipt of a funding agency decision. Box 2 offers an outline for discussions between researchers and patient partners.

\section{Box 2: Outline for Discussions Between Research Teams and Patient Partners}

- Researchers' expectations for partner participation

- Possible role(s)

- Expected time commitment

- Compensation

- Required trainings

- Patients' past experiences and interests

- Anticipated benefits to the patient partner

- Ability to access/use various modes of communication and technology used in the study

One of the authors (G.N.), a patient partner and workshop faculty member, identified two important elements of this phase: 1) providing background on the rationale, goals, hypotheses and expected outcomes of the study; how the data collected will inform those outcomes; and anticipated timelines; and 2) clarifying what is not being studied and what outcomes are not expected. Transparency helps avoid misunderstandings that the goal of the study is to "solve" a particular health problem (e.g. "we're not curing cancer, we're studying the best ways to discuss treatment options with cancer patients").

"It is helpful for the research team to communicate to the patient partner the timeline of the grant process from funding request through approval or rejection at the beginning of the partnership. Then, follow up with contacts communicating the status of the grant in real time."

- Gina Napolitano, patient partner

It is also necessary to train members of the research team in the basics of effective patient engagement in research. Two emergent best practices are to identify one team member to be the partner's consistent point of contact, and review institutional requirements or restrictions on information sharing, data transfers or modes of communication.

\section{Transitioning between preaward and funding} decision: Workshop participants offered insights on how to manage the nascent partnership based on whether or not the study gets funded. Funded studies reconvened patient partners to confirm their participation, reacquaint them with the proposal and timeline, and initiate hiring/contracting, training and other onboarding processes. For unfunded studies, participants recommended individual follow-up with each patient partner to explain the circumstances, including potential resubmission, as well as reassure the partner(s) that the decision does not devalue the validity or importance of their expertise. Offering other opportunities to engage with another research team may be warranted in some cases.

\section{Module II: Caring for the Patient Partner Relationship}

This session covered examples and best practices for maintaining patient engagement during the study. The guiding principles for developing and strengthening the patient-researcher partnership are honesty, transparency and respect. ${ }^{3}$ The workshop drilled down on three tactics: frequent and clear communication, building relationships, and eliciting ongoing feedback from patient partners.

"In the beginning of the engagement, it's the language - boil it down, simplify it on the front end."

- Anonymous patient participant

Frequent and clear communication: Workshop facilitators agreed that regular in-person meetings are optimal for ensuring effective communication, particularly in the early stages. If in-person meetings are not possible, conference calls and webinars are suitable alternatives. Specifying the timing and frequency of project meetings and whether the cadence will change as the study matures shows respect for the patient partner's time. Some study teams observed that impromptu meetings and/or a project newsletter also can enhance relationships 
and connectivity. Patient participants in the workshop noted the importance of determining and accommodating partners' preferred modes and frequency of communication.

Participants underscored the need to explain the study using easy to understand language and avoiding jargon or acronyms to the extent possible. This is critical for communicating with patient stakeholders both verbally and in writing. ${ }^{4}$ The Program for Readability in Science and Medicine (PRISM) initiative created by Group Health Research Institute (Seattle, WA) is a helpful resource to train researchers in using plain language, with a toolkit and online training to improve communication with patients and other audiences. ${ }^{5}$

Sustaining relationships: Participants identified approaches to maintaining strong relationships including: 1) asking patient partners to own and lead certain discussion topics for which their perspectives are uniquely relevant, 2) structuring meetings to allow for informal socializing, 3) using name cards and assigning seats so that people sit next to someone new at each meeting, 4) working through issues in small groups, 5) providing refreshments, and 6) creating a team identity through branded study materials.

One element discussed in the workshop that has received less attention in patient engagement literature is handling "disengagement." Sometimes a patient partner may need to end their involvement in the project, which presents the dilemma of whether to add a new patient partner. A facilitator shared an example of a very committed patient partner who died during the data collection phase. He had participated in the study design and was passionate about the work and his contributions. The research team recruited another patient partner despite the data collection nearing completion. The new partner was able to comment on the findings but was never as engaged as the original patient partner. In contrast, another example involved a patient partner who recused herself partway through the study. The team recruited a new patient partner who helped design the intervention, provided critical feedback and was as involved as the original patient partner. These examples suggest that the phase of the study could inform decisions about whether to replace patient partners who depart a project team.
Eliciting ongoing feedback: Rather than waiting until a study ends to assess patient partners' perspectives on their involvement, workshop attendees recommended getting feedback regularly throughout the project, including brief reactions following in-person team meetings as well as periodic surveys or interviews. Such feedback may uncover both logistical and substantive issues that influence patient partner participation, such as convenience of meeting times, or challenges understanding the study design or methods. Participants observed that this feedback has iteratively informed each new study they undertake with patient partners.

"The mutually beneficial relationship between the researcher and patient partner can add a new dimension to research, making it 'real.' This is key when establishing and maintaining patient partnerships. It is this parallel process that keeps the team engaged; the commitment of the researcher ignites the commitment of the patient partner."

- Gina Napolitano, patient partner

Nurturing patient partner relationships during research projects can lead to connections that extend beyond specific studies to a deeper form of reciprocity between researchers and partners. Patient partners often view researchers as liaisons and advocates within the health care system. A facilitator's example was that of a patient partner who asked a research team to help her plan a workshop at a local senior center on advanced care planning. The research team was able to help her organize the event and connect her with palliative care experts to participate in the workshop.

\section{Module III: Measuring and Assessing Impact of Patient Engagement in Research}

The concluding module focused on the potential outcomes and benefits of engagement, measurement approaches and evidence gaps. Workshop participants noted numerous potential gains from engaging patients in research, including: increased relevance, applicability and credibility of research; personcentered recruitment and retention approaches; greater cultural sensitivity including attentiveness to hard-to-reach populations; accountability of research organizations; patient satisfaction and empowerment; reciprocal understanding and trust between researchers and patients/stakeholders; more effective and 
widespread dissemination/implementation of research findings; patients influencing science that could benefit them or future patients. ${ }^{\text {cf. } 6,7}$ Workshop participants also affirmed the moral obligation to involve patients in the conduct of research, not just as research participants. ${ }^{\text {cf. } 8}$

Measuring patient engagement in research: Few measures have been used to evaluate impact of engagement; hence, empirical support for any promising outcomes is still building. Most existing literature focuses on how engagement affects individual patient partners and on processes of engagement. Less has been reported about the effects, especially longterm, on the spread and use of research findings in everyday life, patient decision-making, health outcomes or other outcomes. To inform this module, facilitators scanned the literature and spoke with stakeholders to identify existing impact assessment tools and presented several measures and frameworks that have potential relevance. Notably, there is little agreement on use of any one instrument or framework, and none is commonly used yet. Three extant frameworks are: 1) the Public Involvement Impact Assessment Framework (PiiAF; www.piiaf.org.uk), 2) Gaglio's application of the Reach Effectiveness Adoption Implementation Maintenance (RE-AIM) framework; ;,10 and 3) AcademyHealth's evaluative framework for patient engagement in research. ${ }^{11}$

Facilitators also summarized four relevant instruments and indicators during the workshop: 1) PCORI's Ways of Engaging - Engagement Activity Tool (WEENACT), ${ }^{12}$ 2) The Guidance for Reporting Involvement of Patients and Public (GRIPP) checklist, ${ }^{13} 3$ ) a National Health Service study by Boote et al. on successful consumer involvement in research, ${ }^{14}$ and 4) an evaluation of community-based participatory research projects by Sandoval et al. ${ }^{15}$ Unfortunately, literature on the use of these frameworks and measures is limited. Moreover, while all have potential utility — as each is thorough, encourages research teams to build ongoing assessment into studies and emphasizes patient partner empowerment - they also are relatively complicated, time-consuming and resource-intensive. Throughout this session, workshop participants explored other measures and agreed to share future experiences with the PER SIG in order to ensure continued development of effective methods.
During this module, small groups of participants engaged in a practical exercise to enumerate patient contributions throughout the research lifecycle. This enabled everyone to consider how they would assess the impact of patient partner involvement at each phase of a project; identify patient partner contributions; consider short-, medium-, and long-term outcomes; and anticipate measurement approaches that could be used throughout the arc of the research project. The tangible end product of this exercise was a populated worksheet on impact, contributions and measurement (Table 1), but the intangible product was a deeper conversation between patients and researchers. The exercise further underscored challenges in measuring impact during project phases.

"I found the experiential piece of the workshop to be quite valuable. My joining a table of researchers offered a brief opportunity to model researcher/patient collaboration and demonstrate how it can enhance a work product rather than impede work flow."

- Gina Napolitano, patient partner

\section{Discussion}

Improving engagement methods was the focus of this workshop. Participants embraced this agenda enthusiastically and suggested several topics for future workshops, including learning more about different roles for patient partners. For example, Robbins et al. have described practical and timely methods to engage patient partners as effective co-investigators, including the adoption of "pre-meeting meetings" to orient them to context and background information on meeting topic(s) and to answer questions. ${ }^{16}$ Workshop participants requested more information on approaches to effective engagement of more sensitive populations (e.g. those with serious illnesses, substance abuse issues, non-English speakers, undocumented immigrants, etc.) and desired further development of methods for successfully co-authoring manuscripts with patient partners.

While Domecq et al. have reported that the most common means of engaging patient partners on research teams were focus groups, interviews, surveys and advisory boards, ${ }^{17}$ workshop participants expressed interest in methods for more active roles for patient partners and for ensuring that their engagement 
Table 1 Workshop Exercise on Patient Partner Contributions, Expected Outcomes, and Measures at Each Phase of a Research Project

\begin{tabular}{|c|c|c|c|}
\hline Phase of project & Patient partner contributions & $\begin{array}{l}\text { Expected outcomes } \\
\text { (short-, mid-, long-term) }\end{array}$ & $\begin{array}{l}\text { Suggested measurement } \\
\text { methods }\end{array}$ \\
\hline $\begin{array}{l}\text { Before funding } \\
\text { and during } \\
\text { proposal writing }\end{array}$ & $\begin{array}{l}\text { - Develop research questions } \\
\text { - Validate and test questions } \\
\text { - Provide guidance on the practicality/ } \\
\text { feasibility of methods }\end{array}$ & $\begin{array}{l}\text { - Funded, successful, } \\
\text { achievable proposal } \\
\text { - Better relationship } \\
\text { between patients and } \\
\text { researchers } \\
\text { - Patients help find sweet } \\
\text { spot in proposals (i.e. } \\
\text { less writing "to the grant") } \\
\text { - Increased trust }\end{array}$ & $\begin{array}{l}\text { - Survey entire team (e.g. } \\
\text { researcher, provider, patients) } \\
\text { - Ask about preconceptions, } \\
\text { hypotheses and potential } \\
\text { impacts of research project } \\
\text { - Assess what changes } \\
\text { happened to the proposal after } \\
\text { patients joined the team } \\
\text { - Ask team if worth it to engage } \\
\text { patient partners on team }\end{array}$ \\
\hline $\begin{array}{l}\text { Once funded, } \\
\text { initial stages } \\
\text { of research } \\
\text { (develop } \\
\text { materials, } \\
\text { process, } \\
\text { questions) }\end{array}$ & $\begin{array}{l}\text { - Review what was funded and verify } \\
\text { questions are still relevant to patients } \\
\text { - Review and pilot test materials and } \\
\text { processes } \\
\text { - Refine how patient partners want to } \\
\text { be involved } \\
\text { - Develop shared communication } \\
\text { strategy and guiding principles } \\
\text { - Develop recruitment strategy }\end{array}$ & $\begin{array}{l}\text { - Research plan is valid } \\
\text { and vetted by patient } \\
\text { partners } \\
\text { - Effective engagement } \\
\text { strategy }\end{array}$ & $\begin{array}{l}\text { - Ask about level of involvement, } \\
\text { quantify participation (e.g. } \\
\text { hours preparing, time spent in } \\
\text { meetings) } \\
\text { - Survey patients about how } \\
\text { they feel engaged; do they feel } \\
\text { heard? } \\
\text { - Assess what changes were } \\
\text { made over time }\end{array}$ \\
\hline $\begin{array}{l}\text { Implement } \\
\text { project and } \\
\text { collect data }\end{array}$ & $\begin{array}{l}\text { - Troubleshoot recruitment and } \\
\text { intervention challenges } \\
\text { - Ensure intervention and data } \\
\text { collection is patient-centered and } \\
\text { relevant } \\
\text { - Interpret problems and successes } \\
\text { - Test data collection instruments }\end{array}$ & $\begin{array}{l}\text { - Inclusive enrollment criteria } \\
\text { (e.g. diverse sample) } \\
\text { - Recruitment targets met } \\
\text { - Participation and retention } \\
\text { - Better overall outcomes } \\
\text { - Early identification of } \\
\text { roadblocks - quicker } \\
\text { resolution of problems } \\
\text { - Improved processes } \\
\text { - Improved validity }\end{array}$ & $\begin{array}{l}\text { - Informal group discussions } \\
\text { - Assess participation and } \\
\text { retention rates } \\
\text { - Evaluate and analyze meeting } \\
\text { minutes }\end{array}$ \\
\hline $\begin{array}{l}\text { Analyzel } \\
\text { interpret data } \\
\text { and write up } \\
\text { results }\end{array}$ & $\begin{array}{l}\text { - Ask patients what they think results will } \\
\text { be before they see them - if different } \\
\text { from their expectations, ask why } \\
\text { - Add context to data (showing "the } \\
\text { whole story"); provide insight into why } \\
\text { there is missing data } \\
\text { - Explain gaps in data } \\
\text { - Train patients in coding and interpreting } \\
\text { qualitative data (e.g. describe what } \\
\text { patients are feeling through their quotes) } \\
\text { - Patients can write up findings for } \\
\text { nonscientific audiences }\end{array}$ & $\begin{array}{l}\text { - Findings are more } \\
\text { relevant to patients' } \\
\text { needs } \\
\text { - Improved "readability" of } \\
\text { write-ups }\end{array}$ & $\begin{array}{l}\text { - Assess comprehension of } \\
\text { results } \\
\text { - Assess how perceptions, } \\
\text { comprehension, opinions, } \\
\text { hypotheses changed }\end{array}$ \\
\hline $\begin{array}{l}\text { Disseminate } \\
\text { (share } \\
\text { results) and } \\
\text { implement (use } \\
\text { intervention or } \\
\text { findings) in new } \\
\text { settings or more } \\
\text { broadly }\end{array}$ & $\begin{array}{l}\text { - Write blog posts } \\
\text { - Identify where and how to share results } \\
\text { (e.g. mainstream magazines, etc.) } \\
\text { - Provide guidance on what information } \\
\text { appeals to the community } \\
\text { - Discuss how to make findings } \\
\text { relevant to patients } \\
\text { - Give access and make connections } \\
\text { to individuals and communities; share } \\
\text { networks } \\
\text { - Break down the message for different } \\
\text { methods of social media outreach } \\
\text { - Create messages to share by word of } \\
\text { mouth } \\
\text { - Express findings in patients' own } \\
\text { voice/words } \\
\text { - Help write patient-centered content } \\
\text { (framing story); identify what is important } \\
\text { to each audience and tailor to them }\end{array}$ & $\begin{array}{l}\text { - Awareness raised in } \\
\text { broader public beyond } \\
\text { usual venues } \\
\text { - Advocacy takes place } \\
\text { - More connections } \\
\text { - More accessible } \\
\text { materials } \\
\text { - Ambassadors and } \\
\text { advocates increase trust } \\
\text { and interest in research } \\
\text { - Increased patient partner } \\
\text { capacity and activation in } \\
\text { their own health care } \\
\text { - Policy change and } \\
\text { messaging in health } \\
\text { care has a more patient- } \\
\text { centered agenda }\end{array}$ & $\begin{array}{l}\text { - Track dissemination (e.g. types } \\
\text { of products, venues, reach, } \\
\text { sharers) } \\
\text { - Assess who used or acted on } \\
\text { the results } \\
\text { - Assess literacy of materials } \\
\text { - Monitor uptake (e.g. website } \\
\text { hits) } \\
\text { - Conduct an environmental } \\
\text { scan } \\
\text { - Assess how relevant } \\
\text { information is beyond } \\
\text { the research team and } \\
\text { stakeholders by surveying } \\
\text { people at community events } \\
\text { - Interview team members }\end{array}$ \\
\hline
\end{tabular}


is substantive and meaningful. The field of patient engagement is maturing and needs to continue to develop and disseminate effective methodologies to accommodate the evolving roles of patient partners on research teams.

"The initial time and effort required to involve patient partners early in the research process can lead to streamlined or more accurately focused desired outcomes that are more meaningful to patients and other stakeholders. It seems worth the longer timelines if it means potentially increasing the validity of the work." - Gina Napolitano, patient partner

As the science of patient engagement in research progresses, there is growing interest in methods to assess its impacts. Recently, Hamilton and True delineated constructs for both processes and impacts that affect health outcomes, the uptake of innovations, changes to study design, and evolution of trust and collaboration. ${ }^{18}$ Process constructs ask what happens in engagement and how, including partner roles and tasks, communication, the level and types of partner involvement in research, influence and powerdynamics, decision-making, dialogue/ listening/respect/cooperation, leadership and governance, and empowerment. Impact constructs, in contrast, try to answer questions about what and who will be changed through engagement, how and when they change and how to assess the magnitude of change. Improving assessment is a necessary corollary to increased involvement of patient partners in research. Our workshop underscored the need for more work to test and validate measures that capture both process and impact data.

\section{Conclusions}

Engaging patients (and other stakeholders) in research requires skills in communication, facilitation, trust building and relationship development that are not commonly associated with scientific research methods. Creating mutually respectful, trusting relationships necessary for meaningful patient engagement takes time, as does the design, implementation, analysis and dissemination of results in collaboration with patient partners. By initiating partnerships very early in the proposal development stage, it is possible to build these essential relationships before a grant timeline begins to define the tempo of the partnership and the deliverables required.
All of the methods discussed during the HCSRN workshop on patient engagement in research incorporate the expectation that researchers acknowledge and accommodate the longer timelines often required by engaging patients in research processes. They also assume that researchers approach the processes with humility and a recognition that the benefits patient partners bring to research are many, varied and frequently unpredictable. These benefits are elusive, however, if the researcher isn't open to truly learning from patient partners. Successful partnerships rely on transparency, honesty and respect among all partners. All aspects of engagement, from logistical arrangements, recruitment and preparation, project implementation and data collection, through analysis and dissemination of results, should be conducted with an emphasis on equality among partners and the belief that patient partners bring expertise their experiences as patients - that is as valid and legitimizing as advanced degrees and peer-reviewed publications.

The goal of patient-centered health care research is to improve patient care. It only makes sense to engage patients in this process.

\section{Patient-Friendly Recap}

- Health researchers are inviting patient partners to bring their expertise as patients to the entire research process.

- A group of researchers and patients hosted a workshop to share ways to develop and maintain relationships with patient research partners. Benefits of these partnerships included improved research questions, process, outcomes and sharing of findings.

- Health researchers and their patient partners should learn the best ways to work together on research teams.

\section{Acknowledgments}

We would like to thank John F. Steiner, MD, MPH, for his review of an early draft of this manuscript and his unwavering support for methods development in patient-engaged research. 


\section{Funding Sources}

Support for this workshop and manuscript was provided by Kaiser Permanente Colorado's Institute for Health Research, Kaiser Permanente Colorado's Community Benefit Department, and the Health Care Systems Research Network. Funding also was provided by the National Health Institutes' (NIH) National Center for Advancing Translational Sciences (Colorado CTSA grant number UL1 TR001082). Contents are the authors' sole responsibility and do not necessarily represent official NIH views.

\section{References}

1. Madrid S, Wright L. Patient engagement workbook (presentation dated Oct. 2, 2014). HCSRN Patient Engagement in Research Scientific Interest Group. www.hcsrn.org/en/Tools\%20\&\%20 Materials/Plan_Field/HCSRNPatientEngagementWorkbook. pdf. Accessed June 13, 2016.

2. CoPPiR home page. www.coppir.org. Accessed June 13, 2016.

3. McNeil H, Elliott J, Huson K, et al. Engaging older adults in healthcare research and planning: a realist synthesis. Research Involvement and Engagement. 2016;2:10. CrossRef

4. Ridpath JR, Wiese CJ, Greene SM. Looking at research consent forms through a participant-centered lens: the PRISM readability toolkit. Am J Health Promot. 2009;23:371-5. CrossRef

5. Ridpath J, Greene S. PRISM online training: a free, customized, effective plain language tutorial for researchers. (abstr.) Clin Med Res. 2012;10(3):169. CrossRef

6. Brigham and Women's Hospital Patient-Centered Comparative Effectiveness Research Center. Patient engagement best practices resource document. www.brighamandwomens. org/Research/centers/PCERC/documents/PCERC\%20 Patient $\% 20$ Engagement $\% 20$ Best $\% 20$ Practices $\% 20$ Resource\%20Document.pdf. Accessed June 13, 2016.

7. Esmail L, Moore E, Rein A. Evaluating patient and stakeholder engagement in research: moving from theory to practice. $J$ Comp Eff Res. 2015;4:133-45.

8. Domecq Garces JP, Prutsky Lopez GJ, Wang Z, et al. Eliciting patient perspective in patient-centered outcomes research: a meta narrative systematic review (report dated 2012). www. pcori.org/assets/Eliciting-Patient-Perspective-in-PatientCentered-Outcomes-Research-A-Meta-Narrative-SystematicReview1.pdf. Accessed June 13, 2016.
9. Gaglio B. Applying RE-AIM to patient and stakeholder engagement (presentation dated March 15, 2016). www.reaim.hnfe.vt.edu/presentations/GaglioMarch2016Slides.pdf. Accessed June 13, 2016.

10. Glasgow RE, Vogt TM, Boles SM. Evaluating the public health impact of health promotion interventions: the RE-AIM framework. Am J Public Health. 1999;89:1322-7.

11. Rein A, Esmail L, Moore E, Thomas V, Sabharwal R. Evaluative framework for patient engagement in research. (abstr.) AcademyHealth 2013 Annual Research Meeting Archives. www.academyhealth.org/files/ARM/2013/A11\%20 Podium\%20Presentations.pdf. Accessed June 13, 2016.

12. Frank L. Ways of Engaging - Engagement Activity Tool (WE-ENACT): preliminary results (presentation dated Dec. 8, 2014). Patient-Centered Outcomes Research Institute Board of Governors Meeting. www.pcori.org/sites/default/files/ PCORI-Ways-of-Engaging-Engagement-ACtivity-Tool-WEENACT-Preliminary-Results-120814.pdf. Accessed June 13, 2016.

13. Staniszewska S, Brett J, Mockford C, Barber R. The GRIPP checklist: strengthening the quality of patient and public involvement reporting in research. Int J Technol Assess Health Care. 2011;27:391-9. CrossRef

14. Boote J, Barber R, Cooper C. Principles and indicators of successful consumer involvement in NHS research: results of a Delphi study and subgroup analysis. Health Policy 2006;75:280-97. CrossRef

15. Sandoval JA, Lucero J, Oetzel J, et al. Process and outcome constructs for evaluating community-based participatory research projects: a matrix of existing measures. Health Educ Res. 2012;27:680-90. CrossRef

16. Robbins M, Tufte J, Hsu C. Learning to "swim" with the experts: experiences of two patient co-investigators for a project funded by the Patient-Centered Outcomes Research Institute. Perm J. 2016;20(2):85-8. CrossRef

17. Domecq JP, Prutsky G, Elraiyah T, et al. Patient engagement in research: a systematic review. BMC Health Serv Res. 2014;14:89. CrossRef

18. Hamilton A, True G. Measuring processes and impacts of veteran-engaged research (presentation dated May 17, 2016). Veteran Engagement Initiative in VA Research Cyberseminar. www.hsrd.research.va.gov/for_researchers/cyber_seminars/ archives/1126-notes.pdf. Accessed June 13, 2016.

(C) 2016 Aurora Health Care, Inc. 